\title{
Article
}

\section{Mathematical modelling of formation process for multi-layer 3D structure produced by additive method using arc heat sources}

\author{
V.A. Kostin ${ }^{1, *}$, G.M. Grigorenko ${ }^{1}$, V.A. Shapovalov ${ }^{1}$, A.N. Pikulin ${ }^{1}$ \\ ${ }^{1}$ E.O. Paton Electric Welding Institute of the NAS of Ukraine \\ Georgy M. Grigorenko; office_22@ukr.net; \\ Viktor A. Shapovalov; shapovalov@paton.kiev.ua; \\ Alexandr N. Pikulin; om.pikulin@gmail.com; \\ * Correspondence: Valery A. Kostin; valerykostinepwi@gmail.com \\ Received: 07.05.2019; Accepted: 08.07.2019
}

\begin{abstract}
The results of modelling of temperature fields, kinetics of deposition of layers of dissimilar metals and nature of structural transformations in formation of multi-layer structure of 17G1S and 30KhGS steels are presented. Computer modelling was performed using COMSOL Multiphysics software package. The work takes into account effect of temperature on thermal and physical parameters of steels. Two highstrength structural steels, namely 17G1S and 30KhGS with different level of physical-mechanical properties and nature of initial microstructure (Fig. 2) were taken as a material for computer simulation. Thermal and mechanical properties of simulated alloys $17 \mathrm{G} 1 \mathrm{~S}$ and $30 \mathrm{KhGS}$ (Table I) were calculated by OpenCALPHAD program.
\end{abstract}

Keywords: additive manufacturing; arc cladding; mathematical modelling

\section{Introduction}

Almost all modern industry is based on casting and cutting technologies. At the beginning the metallurgical methods help to form a billet, which further is subjected to mechanical treatment (cutting, deformation, forging) and structure elements are developed. This is so called "subtraction technologies". Over the last years a new complex of technologies, namely addition or additive technologies $[1 \div 3]$, has received a large development. In contrast to casting and cutting technologies, additive manufacturing is based on addition of small portions of material. The products are created due to melting of metallic powder [4], solid wire or flux-cored wire [5,6] with concentrated power sources. The combination of an electric arc as heat source and wire as feedstock is referred to as WAAM and has been investigated for AM purposes since the 1990s [7].

Using a metallic wire in the additive process, on the one hand, allows increasing efficiency of metallurgical processes, provide higher energy-efficiency, rise material recovery, guarantee ecological safety, and, on the other hand, makes it possible to create the products of a shape, composition and structure, which cannot be in principle provided by traditional technologies. From point of view of formation of deposited metal structure, application of additive methods allows forming more uniform and dispersed polycrystalline or crystallographically perfect single-crystalline metal structure in comparison with traditional cast one (Fig. 1). Additive methods are characterized with absen-ce of chemical inhomogeneity, dendrite and zone segregation that is related with small size of liquid pool and high solidification rate of deposited metal [8].

In the recent time the material engineers face with the problems of development of the new technological processes providing the materials with high complex of properties at impact, wear and fatigue, subjected to increased cyclic and alternating loads. Functionally graded materials $[9,10]$ are referred to such materials having unique set of mechanical, technological and special properties. The functionally-graded materials are a new class of materials, characterized by gradual or periodic change of mechanical properties and composition on material depth. Today, the functionally graded materials (FGM) are mostly produced from high-strength steels, aluminum and titanium alloys, as well as ceramics.

Traditionally gradient structures are produced by means of application of special technologies of chemical-thermal surface treatment, surface hardening, layer-by-layer pressing with further vacuum sintering, electron-beam deposition, application of different coatings and deposits. The disadvantage of all these technologies is relatively small thickness of areas with gradient structures, their inhomogeneity and instability 
of properties, presence of high internal stresses. If these disadvantages are eliminated, FGM can find application in military equipment, metal processing, mining and refining industry etc. In view of this it is reasonable to evaluate the possibility of application of additive technologies for development of new FGM. In order to increase efficiency of the process of product additive formation simultaneous application of a group of concentrated heat sources is possible at small portion feeding of metal compatible with a matrix. There can be a lot of such heat sources uniformly located over the perimeter of part being built up.

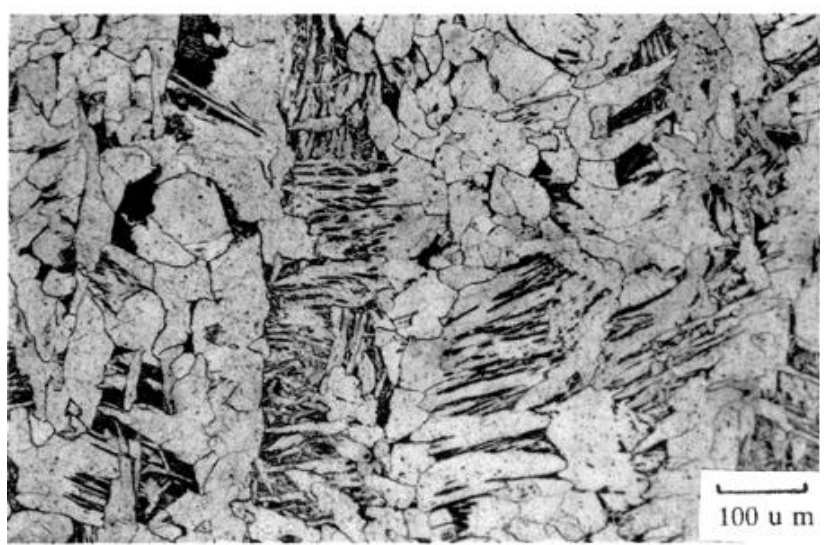

(a)

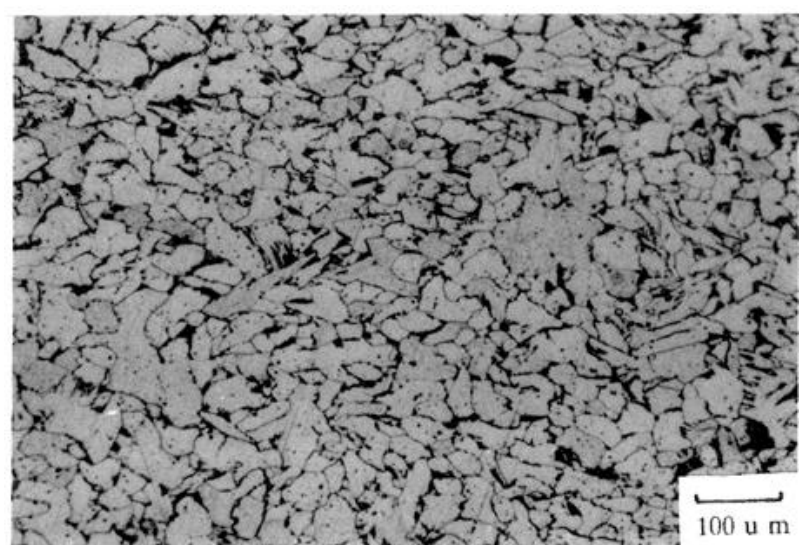

(b)

Fig. 1. Microstructure of deposited layers of steel 09G2S, produced by different methods: a) traditional casting method; b) electric arc additive manufacturing. Magnification x 500

In this connection it is interesting to study mutual effect of heat sources on each other, which will allow formulating the requirements to minimum and maximum permissible distances between the sources and their powers. This is sufficiently difficult engineering and technological problem. Therefore, prior to performance of the real full-scale experiments it is reasonable to carry out computation experiments using the mathematical modeling methods. This work considers application of 3 heat sources.

The aim of the work lied in analysis of the possibilities of application of additive forming technology of structures from functional materials with different complex of physical-mechanical properties.

\section{Material and investigation procedure}

The additive manufacturing technology allows effective and economy development and replacement of damaged parts of highly-loaded assemblies directly in place. Following from this, two high-strength structural steels, namely 17G1S and 30KhGS with different level of physical-mechanical properties and nature of initial microstructure (Fig. 2) were taken as a material for computer simulation.

Structural low-alloy steel 17G1S is used in welded structures in shipbuilding, machine building, main gas- and oil pipelines, in welded joints operating under high pressure at temperature from -40 to $+475{ }^{\circ} \mathrm{C}$. Structure of steel 17G1S is ferrite-pearlite. Chemical composition of steel 17G1S (wt.\%) is the following $0.17 \%$ C, $1.52 \% \mathrm{Mn}, 0.47 \mathrm{Si}, 0.02 \% \mathrm{~S}, 0.025 \% \mathrm{P}$. Mechanical properties are the next ones, namely yield strength 343 $\mathrm{MPa}$, ultimate strength $490 \mathrm{MPa}$; relative elongation $20 \%$. Temperatures of the critical points make $\mathrm{Ac}_{1}=745$ ${ }^{\circ} \mathrm{C}, \mathrm{Ac}_{3}=870^{\circ} \mathrm{C}, \mathrm{Ar}_{1}=680^{\circ} \mathrm{C}, \mathrm{Ar}_{3}=790^{\circ} \mathrm{C}$.

Structural alloy steel $30 \mathrm{KhGS}$ is used in the critical welded structures operating at alternating loads, fasteners operating at low temperatures, gear wheels, flanges, casing bodies, blades of compressor machines. Structure of $30 \mathrm{KhGS}$ steel is bainite-martensite. Chemical composition of $30 \mathrm{KhGS}$ steel (wt.\%) is the following $0.32 \% \mathrm{C}, 1.1 \% \mathrm{Mn}, 1.05 \% \mathrm{Cr},<0.3 \% \mathrm{Ni},<0.3 \% \mathrm{Cu}, 0,02 \% \mathrm{~S}, 0.025 \% \mathrm{P}$. Mechanical properties are the next ones, namely yield strength $580 \mathrm{MPa}$, ultimate strength $686 \mathrm{MPa}$, relative elongation $11 \%$. Temperatures of the critical points make $\mathrm{Ac}_{1}=760{ }^{\circ} \mathrm{C}, \mathrm{Ac}_{3}=830^{\circ} \mathrm{C}, \mathrm{Ar}_{1}=670{ }^{\circ} \mathrm{C}, \mathrm{Ar}_{3}=705^{\circ} \mathrm{C}, \mathrm{M}_{\mathrm{H}}=352^{\circ} \mathrm{C}$.

Microstructure of steels 17G1S and 30KhGS in as-delivery condition is presented in figure 2. Content of ferrite in steel $17 \mathrm{G} 1 \mathrm{~S}$ made $52 \%$, pearlite $48 \%$ and that in steel $30 \mathrm{KhGS}$ was $60 \%$ for bainite and $40 \%$ for martensite. To carry out computer simulation of the additive manufacturing process it is necessary to take into account dependence of the physical-metallurgical properties of steels being simulated on heating temperature. In addition to tradition methods used to receive the properties of materials in course of experimental investigations, the most perspective now is application of free or commercial software for modelling of a wide spectrum of properties of multi-component steels and alloys based on CALPHAD method [11]. 


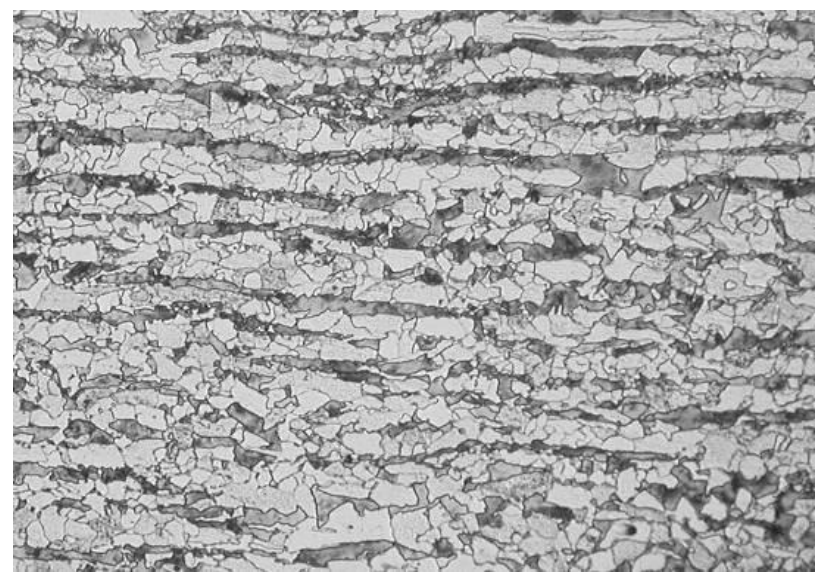

(a)

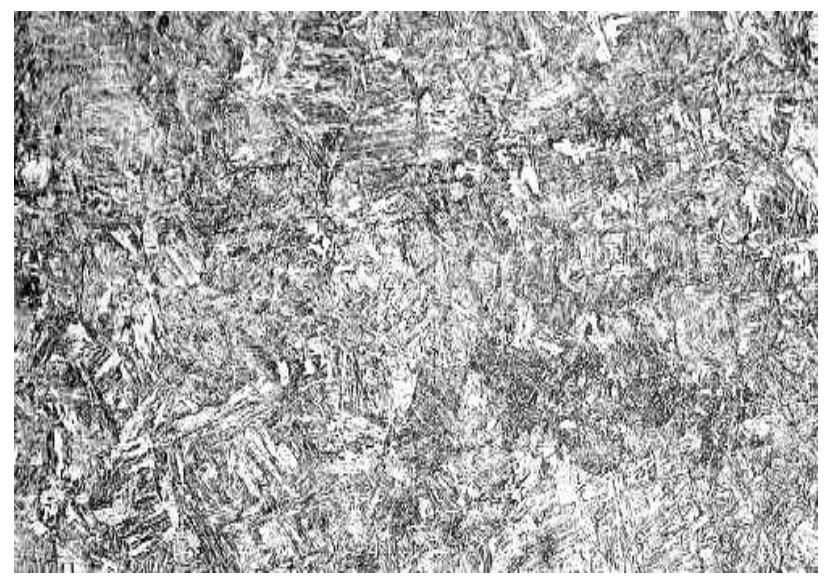

(b)

Fig. 2. Microstructure of a) $17 \mathrm{G} 1 \mathrm{~S}$ and b) $30 \mathrm{KhGS}$ steel specimens in as-delivered condition. $\mathrm{x} 200$

FactStage, MTDATA, Thermo-Calc and OpenCALPHAD commercial programs are referred to such types of software first of all. Thermal and mechanical properties of simulated alloys 17G1S and 30KhGS (Table I) were calculated by OpenCALPHAD program. Multidisciplinary package COMSOL Multiphysics was used for computer modelling [12]. It allows joining the problems of diffusion, heat- and mass transfer, hydrodynamics and mechanics of deformable solid body in one interconnected problem. The following physical interfaces, namely heat-transfer module, diffusion module, structural mechanics module and module of differential equation solution in partial derivatives were used in the process of modelling.

Geometry of structure wall consists of the alternating layers of material from steel 17G1S and 30KhGS of $1.0 \mathrm{~mm}$ thickness, $6.0 \mathrm{~mm}$ width and $280 \mathrm{~mm}$ length (Fig. 3a). Number of deposited layers was determined from the condition of maximum approximation to stationary temperature mode of deposition application. Based on the results of previous investigations [13] the number of layers makes from 6 to 8 layers. Alternating deposition of 10 steel layers was modeled in the work.

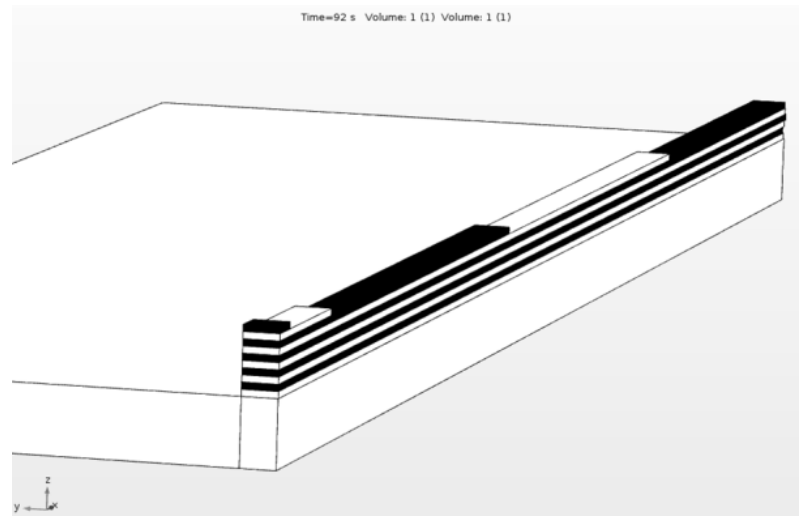

(a)

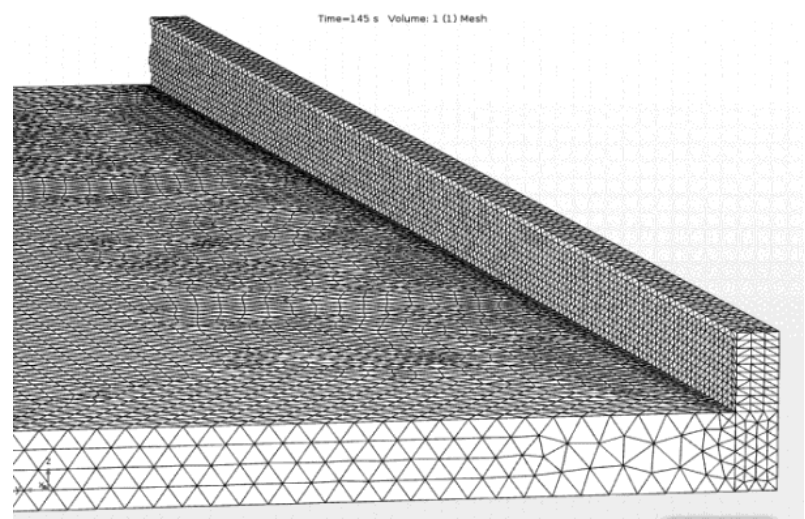

(b)

Fig. 3. a) Geometry of additive forming b) and computational mesh (for steel 17G1S, 30KhGS)

Following the results of experiment, it was accepted that in the initial moment of time the deposited material is in a solid-liquid state between liquidus and solidus temperatures for these steels that allows disregard a liquid phase during formation of layers in the calculations. The layers were one by one deposited on the substrate with 10 seconds interval.

Three arc heat sources were simultaneously used in the work in order to increase efficiency of the additive process, provide homogeneity of temperature distribution, prevent early cooling of the deposited layer before deposition of further layer due to their small thickness $(\sim 1 \mathrm{~mm})$, and develop the possibility to regulate composition of part being deposited. The idea of simultaneous application of several arc heating sources is based on the experience of application of multi-arc submerged-arc welding, at which welding wires of different composition are set on the separate arc that allows regulating temperature, content of alloying elements and weld metal microstructure with high accuracy [14]. The necessary weld composition is reached by means of variation of number of arcs with welding wire of that or another alloying system and different speed of its feeding on separate arcs. Such an approach provides more favorable structure state 
of the weld metal (formation of acicular ferrite) and, as a result, higher mechanical properties of welded joint. A model of elastic-plastic material was considered in the calculations. Stresses and deformations in the model appear as a result of development of sag phenomena due to material volume reduction in cooling.

Table I. Effect of heating temperature on thermal-physical properties of steels 17G1S and 30KhGS

\begin{tabular}{|c|c|c|c|c|c|c|c|c|c|}
\hline \multicolumn{5}{|c|}{ Steel 17G1S } & \multicolumn{5}{|c|}{ Steel 30KhGS } \\
\hline \multicolumn{3}{|c|}{ Physical properties } & \multicolumn{2}{|c|}{ Thermal properties } & \multicolumn{3}{|c|}{ Physical properties } & \multicolumn{2}{|c|}{ Thermal properties } \\
\hline 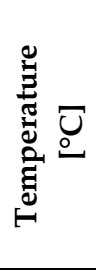 & صే & 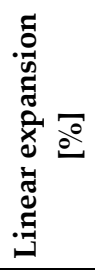 & 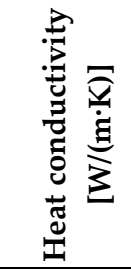 & 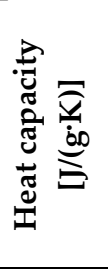 & 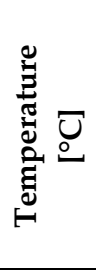 & 营 & 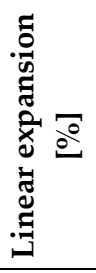 & 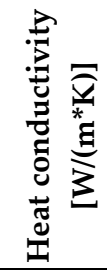 & 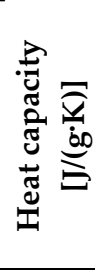 \\
\hline 25 & 7.80 & 0.00 & 32.65 & 0.45 & 25 & 7.78 & 0.00 & 22.25 & 0.46 \\
\hline 100 & 7.78 & 0.10 & 34.54 & 0.48 & 100 & 7.75 & 0.10 & 24.44 & 0.49 \\
\hline 200 & 7.75 & 0.23 & 36.11 & 0.52 & 200 & 7.72 & 0.23 & 27.11 & 0.53 \\
\hline 300 & 7.72 & 0.37 & 36.51 & 0.57 & 300 & 7.69 & 0.38 & 29.10 & 0.57 \\
\hline 400 & 7.68 & 0.53 & 35.82 & 0.62 & 400 & 7.66 & 0.53 & 30.11 & 0.63 \\
\hline 500 & 7.65 & 0.68 & 34.38 & 0.70 & 500 & 7.62 & 0.69 & 30.12 & 0.70 \\
\hline 600 & 7.61 & 0.85 & 32.60 & 0.80 & 600 & 7.58 & 0.86 & 29.30 & 0.83 \\
\hline 700 & 7.57 & 1.02 & 30.94 & 0.96 & 700 & 7.54 & 1.03 & 28.23 & 1.01 \\
\hline 800 & 7.59 & 0.94 & 27.12 & 0.87 & 800 & 7.56 & 0.94 & 25.11 & 0.62 \\
\hline 900 & 7.55 & 1.09 & 27.53 & 0.61 & 900 & 7.50 & 1.18 & 26.24 & 0.64 \\
\hline 1000 & 7.50 & 1.34 & 28.71 & 0.63 & 1000 & 7.44 & 1.41 & 27.38 & 0.63 \\
\hline 1100 & 7.45 & 1.59 & 29.89 & 0.64 & 1100 & 7.39 & 1.65 & 28.53 & 0.65 \\
\hline 1200 & 7.39 & 1.84 & 31.07 & 0.66 & 1200 & 7.34 & 1.90 & 29.68 & 0.66 \\
\hline 1300 & 7.34 & 2.10 & 32.25 & 0.68 & 1300 & 7.28 & 2.16 & 30.83 & 0.68 \\
\hline 1400 & 7.28 & 2.36 & 33.43 & 0.69 & 1400 & 7.22 & 2.48 & 31.96 & 1.44 \\
\hline
\end{tabular}

Owing to the fact that the calculation area continuously increased in size because of constant addition of the new wire elements, rearrangement of the computational mesh took place at every modelling step. In the process of calculation, the number of mesh elements has risen from $~ 250.000$ to 630.000 elements. Method adaptive mesh was used in the calculation, size of cell in which does not exceed $0.1 \mathrm{~mm}$ in the deposited layer and $1 \mathrm{~mm}$ in the substrate (Fig. 3b). Used model and corresponding to it mathematical equations are given in works [13,15]. 3D non-stationary heat conduction equation (1) was solved for numerical analysis of kinetics of temperature field change in the deposited product with time:

$$
\rho C_{p}\left(\frac{\partial T}{\partial t}+u \cdot \nabla T\right)=\nabla \cdot[k(T) \nabla T]
$$

$\rho C_{p}$ is the specific heat capacity and $k$ is the heat conduction coefficient of the material.

The boundary conditions, necessary for solution of equation (1) are determined by a balance of heat input and heat sink from the surface of part being deposited. Thus, the heat sink in the contact area of part being deposited with the substrate can be described by Newton law, whereas thermal radiation on the free surface is regulated by Stefan-Boltzmann law.

The boundary conditions for solution of heat conduction equation (1) have the following form:

$$
-k(T) \frac{\partial T}{\partial n}=\left\{\begin{array}{l}
h\left(T-T_{e x t}\right), \\
\text { in the area of contact with substrate } \\
h\left(T-T_{e x t}\right)+\varepsilon \sigma_{o}\left(T^{4}-T_{e x t}^{4}\right)-q_{a r c}-q_{\text {wire }}, \\
\text { on free surfaces }
\end{array}\right.
$$

where:

$n$ is the normal to the surface,

$h=10\left(\mathrm{~W} / \mathrm{m}^{2} \cdot \mathrm{K}\right)$ is the coefficient of convective heat conductivity,

$\varepsilon=0.8$ is the material emissivity factor, 
$\sigma_{o}$ is the Stephan-Boltzmann constant $\left(5.6704 \cdot 10^{-8} \mathrm{~J} \cdot \mathrm{s}^{-1} \cdot \mathrm{m}^{-2} \cdot \mathrm{K}^{-4}\right)$,

$T_{e x t}=293 \mathrm{~K}$ is the temperature of ambient environment,

qarc is the density of heat flow developed by arc heat source,

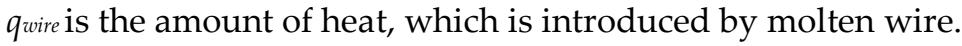

A model of joint transfer of energy from two simultaneously acting heat sources, namely arc source and molten wire, was used in the work. Distribution of density of a heat flow from moving surface arc source qarc $(x, y, t)$ was set by a model of ellipsoidal type:

$$
q_{\text {arc }}(x, y, t)=q_{\max } \exp \left[-K_{x}\left(x-x_{0}-v_{a} * t\right)^{2}-K_{y}\left(y-y_{0}\right)^{2}\right]
$$

where:

$x, y$ are the local coordinates of heat source,

$x_{0}, y_{0}$ are the initial coordinates of the source,

$q_{\max }=\eta U_{a} I_{w}$ is the source power,

$\eta$ is the performance factor $(0.9 \ldots 0.95)$ of source;

$U_{a}$ is the arc voltage;

$I_{w}$ is the arc current;

$K_{x}$ and $K_{y}$ are the coefficients of concentration of specific heat source,

$v_{a}$ is the velocity of arc source along axis $X, t$ is the time.

Distance between the neighbor arc sources made $100 \mathrm{~mm}$.

Distribution of density of the heat flow from molten wire $q_{\text {wire }}(\mathrm{x}, \mathrm{y}, \mathrm{t})$ was set by movement of an edge of forming layer with $v_{a}$ speed having constant temperature equal to $T_{\text {wire }}=1800 \mathrm{~K}$.

In the presented work this model was expanded by diffusion equation due to high possibility of appearance of the diffusion processes between deposited layers of different composition. For this process a diffusion equation (Fick's law) has the following form:

$$
\frac{\partial c_{i}}{\partial t}+\vec{\nabla}\left(-D_{i}\left(T, c_{i}\right) \cdot \vec{\nabla} c_{i}\right)=f_{i}\left(c_{i}\right)
$$

where:

$C_{i}$ is the concentration of $i^{\text {th }}$ element $(i=C, S i, M n)$ in solid solution of iron at the moment of time $t[\mathrm{~s}]$;

$D_{i}$ is the coefficient of diffusion of $i^{\text {th }}$ element $\left[\mathrm{cm}^{2} / \mathrm{s}\right]$;

$T$ is the temperature in a random point of deposition, which is determined based on a solution of temperature problem;

function of volume source $f_{i}\left(c_{i}\right)=0$, due to the fact that no new phases are formed in the deposited bead since content of the elements in a solid solution does not exceed their solubility in iron.

The initial conditions for this process is an initial concentration $c_{i}^{o 1}$ of $(\mathrm{C}, \mathrm{Si}, \mathrm{Mn})$ elements in 17G1S steel and $c_{i}^{o 2}$ in steel 30KhGS. For equation (4) the boundary conditions of deposited layer are periodically changed depending on deposited metal composition, i.e. 17G1S $\left(c_{i}^{o 1}\right)$ or 30KhGS $\left(c_{i}^{o 2}\right)$.

It is known fact that the diffusion coefficient $D_{i}$ depends on temperature and composition of metal in the considered zone as well as on structure state of metal, in which diffusion processes take place. The equations for diffusion coefficients in austenite or ferrite are significantly different. Lower values of the diffusion coefficients in BCC lattice ( $\alpha$-Fe) in comparison with FCC lattice $(\gamma-\mathrm{Fe})$ are related with its higher compactness. The results presented in work [16] were used for calculation of $\mathrm{C}, \mathrm{Si}$ and $\mathrm{Mn}$ diffusion coefficients in $\gamma$-iron. In calculations $D_{i}^{\gamma}(T)$ diffusion coefficients can be presented in form of:

$$
D_{i}^{\gamma}(T)=D_{i 0}^{\gamma} \times \exp \left(-\frac{Q_{i}^{\gamma}}{R T}\right)
$$

where:

$D_{i 0}^{\gamma}$ is the constant, value of which depends on carbon content [ $\left.\mathrm{cm}^{2} / \mathrm{s}\right]$ (Table II);

$Q_{i}^{\gamma}$ is the energy activation of diffusion [J/mole];

$R$ is the universal gas constant $8.31[\mathrm{~J} /($ mole $\cdot \mathrm{K})]$;

$T$ is the temperature $[\mathrm{K}]$.

Well-known empirical dependence of C.A. Wert, received as a result of generalization of large number of experimental data, was used for calculation of coefficients of carbon diffusion in $\alpha$-iron.

$$
D_{C}^{\alpha}(T)=2 * 10^{-6} \exp \left(-\frac{84300}{R T}\right)\left[\mathcal{M}^{2} / c\right]
$$

The calculations made on dependence (6) give the values of carbon diffusion coefficient at $800{ }^{\circ} \mathrm{C}$ $-1.56 \cdot 10^{-6}\left[\mathrm{~cm}^{2} / \mathrm{s}\right]$, at $600{ }^{\circ} \mathrm{C}-1.80 \cdot 10^{-7}\left[\mathrm{~cm}^{2} / \mathrm{s}\right]$, at $200^{\circ} \mathrm{C}-9.70 \cdot 10^{-12}\left[\mathrm{~cm}^{2} / \mathrm{s}\right]$. 
Table II. Values of diffusion coefficients of carbon, manganese and silicon in $\gamma$-iron [16]

\begin{tabular}{|c|c|c|c|c|c|c|}
\hline \multirow{2}{*}{ Element } & \multirow{2}{*}{$\begin{array}{c}\text { Carbon } \\
\text { content }[\%]\end{array}$} & \multicolumn{3}{|c|}{$D_{i}^{y}(T) 10^{7}\left(\mathrm{~cm}^{2} / \mathrm{s}\right)$ at $\mathrm{T}\left[{ }^{\circ} \mathrm{C}\right]$} & \multirow{2}{*}{$\begin{array}{c}D_{i 0}^{y}\left(T \times 10^{7}\right) \\
{\left[\mathrm{cm}^{2} / \mathrm{s}\right]}\end{array}$} & \multirow{2}{*}{$\begin{array}{c}Q_{i}^{y} \\
{[J / m o l e]}\end{array}$} \\
\hline & & 1000 & 1100 & 1200 & & \\
\hline \multirow{3}{*}{ C } & 0.2 & 2.45 & 6.06 & 13.10 & 0.056 & \multirow{3}{*}{128100} \\
\hline & 0.4 & 3.36 & 7.95 & 17.30 & 0.076 & \\
\hline & 0.7 & 4.11 & 10.50 & 23.10 & 0.096 & \\
\hline \multirow{3}{*}{$\mathrm{Si}$} & 0.2 & 2.08 & 5.24 & 11.50 & 0.06 & \multirow{3}{*}{134000} \\
\hline & 0.4 & 2.76 & 7.00 & 15.30 & 0.08 & \\
\hline & 0.7 & 3.80 & 9.58 & 21.00 & 0.11 & \\
\hline \multirow{3}{*}{$\mathrm{Mn}$} & 0.2 & 2.62 & 6.47 & 14.50 & 0.07 & \multirow{3}{*}{132400} \\
\hline & 0.4 & 3.30 & 8.10 & 18.20 & 0.08 & \\
\hline & 0.7 & 4.20 & 10.40 & 23.20 & 0.11 & \\
\hline
\end{tabular}

Solution of the differential equations was carried out on finite element method (FEM) by means of building of a non-uniform adaptive grid and setting in each grid cell of Lagrange interpolation polynomial of the second order. Since deposit geometry has a symmetric form, then the calculation was carried for half of the part in order to decrease calculation resources. Amount structural constituents, forming in the process of polymorphous transformation was calculated by:

$$
V_{j}(T)=V_{j}^{\max }\left(\Delta t_{8 / 5}\right) \cdot f_{j}(T)
$$

where:

$V_{j}(T)$ is the portion of $j$-th phase (ferrite, bainite, martensite);

$V_{j}^{\max }(\Delta) t_{8 / 5}$ is the maximum portion of $j$-th phase;

$\Delta_{8 / 5}$ is the cooling time in a temperature interval $800 \div 500{ }^{\circ} \mathrm{C}$;

$f_{i}(T)$ is the function depending on temperature [14]

A dependence of maximum phase fraction of $V_{j}^{\max }(\Delta) t_{8 / 5}$ from cooling rate $W_{8 / 5}$ for investigated steels (Fig. 4) was determined experimentally by Gleeble 3800 system.

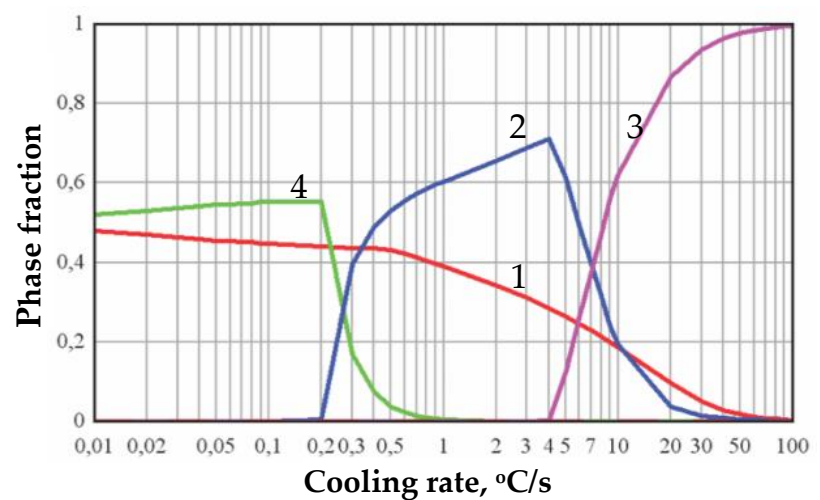

(a)

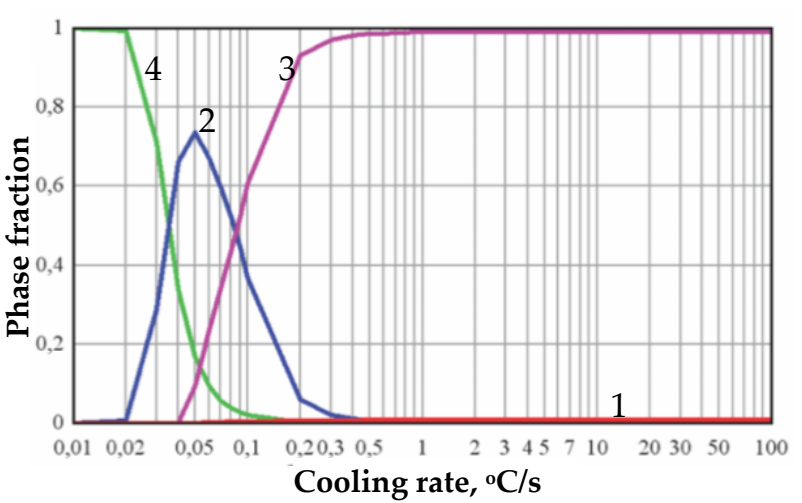

(b)

Fig. 4. Effect of cooling rates $W_{8 / 5}$ on formation of structural constituents $V_{j}^{\max }(\Delta) t_{8 / 5}$ in steels: a) $\left.17 \mathrm{G} 1 \mathrm{~S}, \mathrm{~b}\right) 30 \mathrm{KhGS}$ ( 1 - ferrite, 2 - bainite, 3 - martensite, 4 - pearlite)

\section{Modelling results}

By results of solution of the heat problem a spatial distribution of the temperature fields was built in the different time moments.

The work analyses the effect of heat input from the arc heat source of 1 and $5 \mathrm{~kW}$ power on the temperature field of the deposited layers and kinetics of structure formation. Selection of power of the arc heat source was determined by typical characteristics of electric arc welding process of high-strength lowalloy steels. Table III presents the values of technological parameters arc deposition used in the work.

Preliminary calculations showed that deposition of liquid metal of molten wire on "cold" substrate with $+20{ }^{\circ} \mathrm{C}$ temperature provokes appearance of significant stresses 300 $\div 500 \mathrm{MPa}$ at the boundary between the substrate and deposited bead, which can result in formation of cracks and tear of deposited layers. Due to this, in course of calculations passing of the $1^{\text {st }}$ arc was not accompanied by deposition of liquid metal 
from wire, and the arc in "idle" run only warmed up the substrate. Temperature of the substrate to the moment of arrival of the $2^{\text {nd }}$ arc, at which liquid metal of molten wire was already deposited, made $200 \div 250{ }^{\circ} \mathrm{C}$. Such an approach allowed reducing stresses on substrate-bead boundary to $50 \div 70 \mathrm{MPa}$. To get such an effect in single-arc deposition is virtually impossible due to the fact that the substrate is almost completely cooled to the initial temperature in the moment of wire deposition. Small time (10 s) between arc passing in the proposed model prevents substrate complete cooling.

Table III. Technological parameters of arc deposition

\begin{tabular}{lc}
\hline \multicolumn{1}{c}{ Parameter } & Values \\
\hline Arc power, $\mathrm{kW}$ & $1 \ldots 5$ \\
Thickness of plate, mm & 10 \\
Thickness of deposited layer, mm & 1 \\
Deposit width, mm & 4 \\
Deposit length, mm & 300 \\
Rate of arc movement, mm/s & 10 \\
Rate of wire feed, mm/s & 10 \\
Distance between the sources, mm & 100 \\
Number of deposited layers & 10 \\
\hline
\end{tabular}

Results of modeling of temperature fields in deposition of 10 layers of dissimilar materials are given in figure 5. Analysis of interaction of the temperature fields in the process of deposition allows limiting a time of passing of neighbor heat sources. The calculations show that this time cannot be less than $3 \div 5 \mathrm{~s}$ due to the fact that otherwise overlapping of the liquid metal pools from neighbor sources, increase of pool overheating, its spread on the deposit wall and formation of defects will take place. On the other hand, time between the neighbor sources cannot be higher than $25 \div 30 \mathrm{~s}$ due to the fact that otherwise deposited wall will completely cool down and martensite structure will be formed. This results in rise of stresses on the boundary between the layers and possible defect formation.

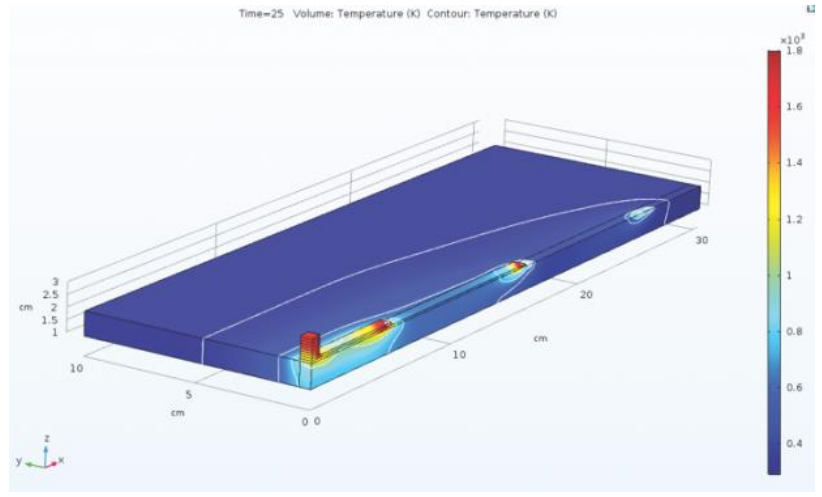

(a)

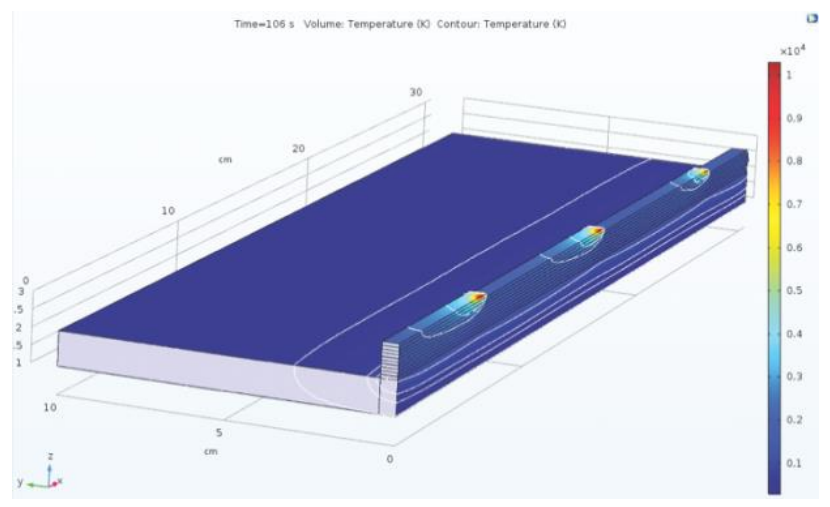

(c)

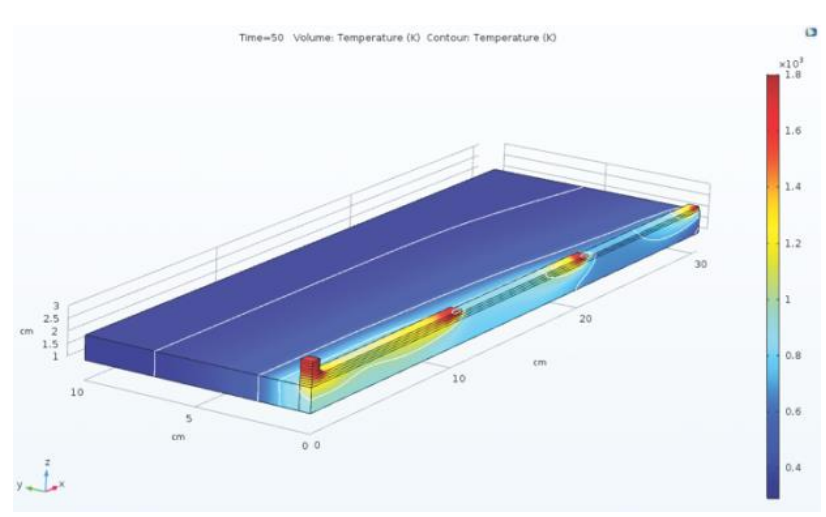

(b)

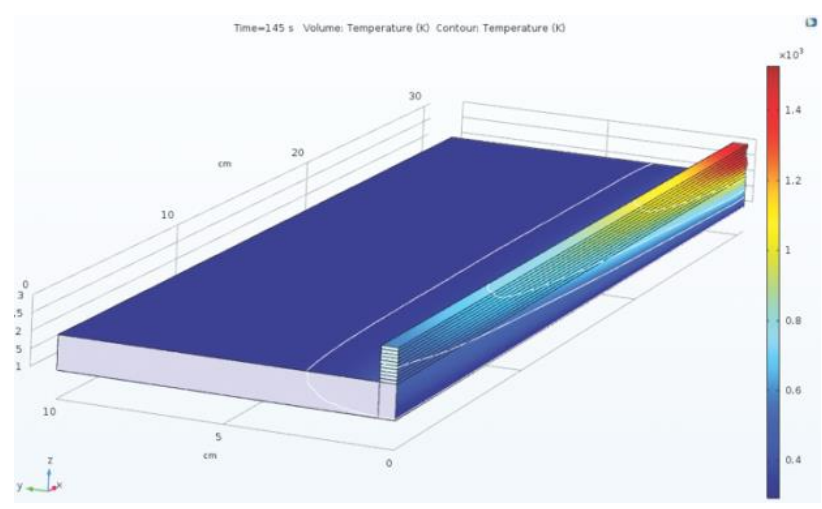

(d)

Fig. 5. Modelling of additive process in time: a) $25 \mathrm{~s}$; b) $50 \mathrm{~s}$; c) $106 \mathrm{~s}$; d) $145 \mathrm{~s}$

Analysis of received results shows almost uniform distribution of temperature in the deposited layers and substrate. Increase of power of heat source from 1 to $5 \mathrm{~kW}$ results in rise of heat affected zone from 1.5 to 3 
$\mathrm{cm}$, respectively. Heating-up of the substrate in process of deposition (Fig. 6) rises and more expressed change of structure-phase composition of the whole part is observed.

Figure 6 shows calculation distribution of substrate temperature on height. Obtained results show that the highest temperature of substrate makes $1220^{\circ} \mathrm{C}$ when using the arc of $1 \mathrm{~kW}$ power, and $1800{ }^{\circ} \mathrm{C}$ at arc power $5 \mathrm{~kW}$. Thus, application of $5 \mathrm{~kW}$ arc provokes submelting of the substrate, whereas it does not happen using $1 \mathrm{~kW}$ power arc. Analysis of the temperature isotherms (Fig. 6b) shows that the areas located at a distance larger than $0.5 \mathrm{~cm}$ from deposit surface are not melted. The maximum temperatures at each disposition cycle are gradually reduced, however it is non-uniform at low arc power $1 \mathrm{~kW}$. This circumstance shall result in formation of inhomogeneity in the deposit structure.

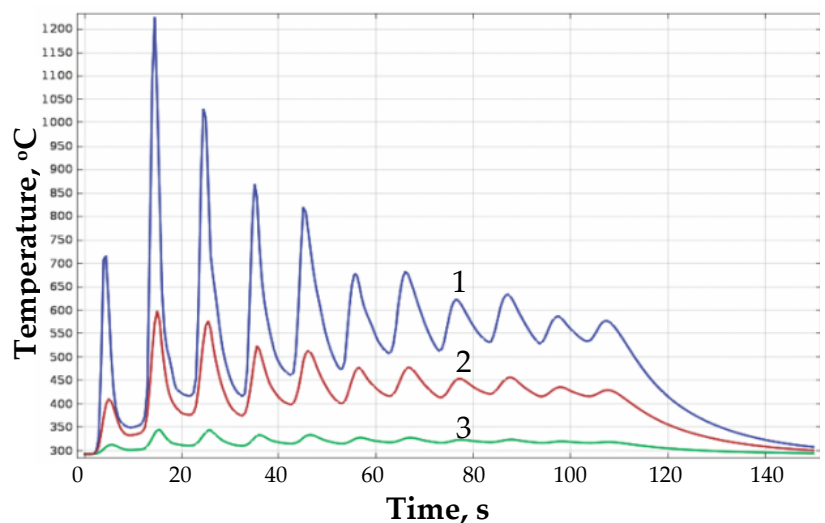

(a)

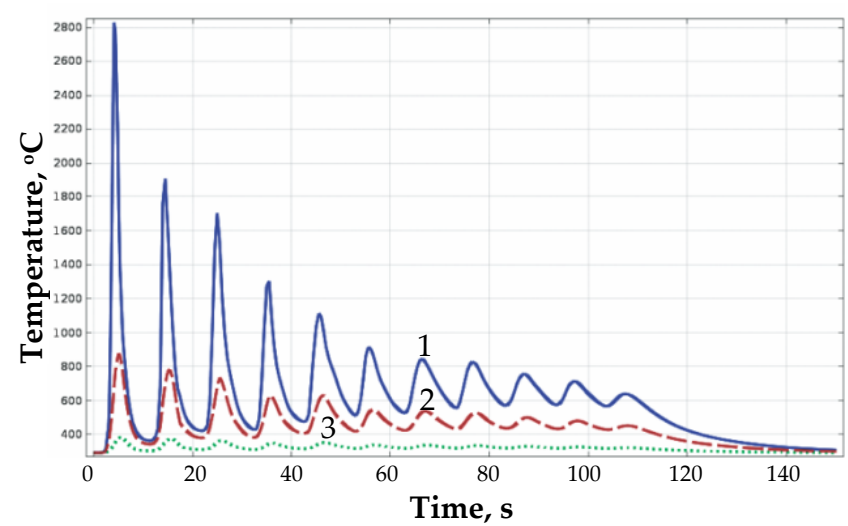

(b)

Fig. 6. Effect of heat input on change of substrate temperature on height $(1-0.1 \mathrm{~mm} ; 2-0.5 \mathrm{~mm} ; 3-0.9 \mathrm{~mm})$ in the process of layers deposition: a) $1 \mathrm{~kW}$ and b) $5 \mathrm{~kW}$

Investigation of structure-phase state of the deposit is presented in figure 7 . The results of modelling show that increase of arc heat input in deposition results in noticeable change of deposit's structure state. Thus, use of low power arc provokes mainly formation of ferrite-bainite structure. After deposition is completed (Fig. 7a) portion of bainite makes $71 \%$, ferrite $28 \%$, martensite $\sim 1 \%$. Bainite-martensite structure is formed at high arc power $5 \mathrm{~kW}$. Portion of bainite in the deposit reduces to $49 \%$, that of martensite rises to $42 \%$ and ferrite drops to $9 \%$ (Fig. 7 b).

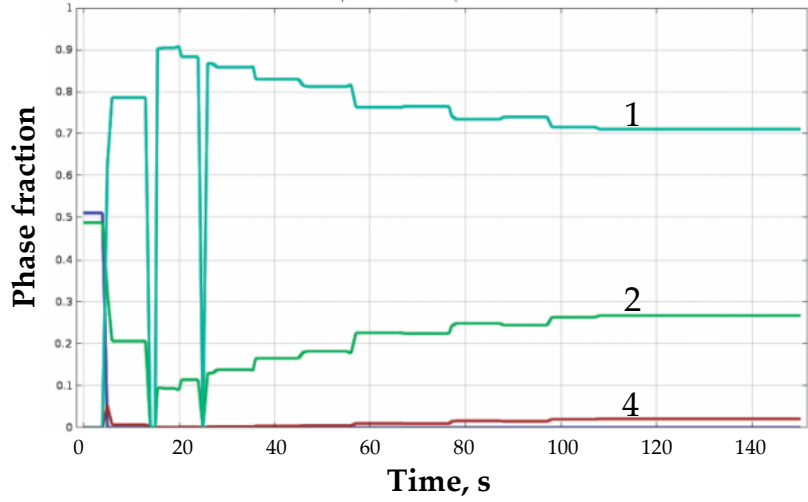

(a)

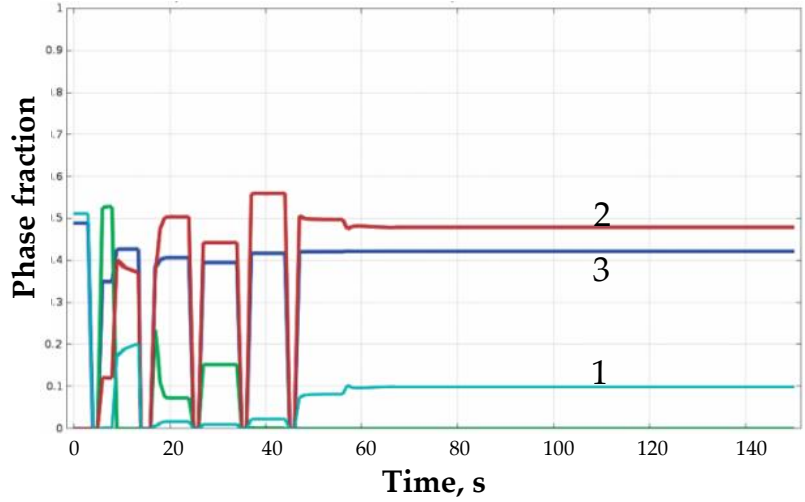

(b)

Fig. 7. Effect of arc heat input on phase change in deposit in time: a) $1 \mathrm{~kW}$ and b) $5 \mathrm{~kW} ; 1$ - ferrite, 2 - bainite, 3 martensite, 4 - pearlite

Change of deposit structure is related with difference in part cooling rates. Though cooling rate of the deposit is cyclically changed (Fig. 6) in deposition with arc of $1 \mathrm{~kW}$, nevertheless on average it makes $8 \div 10{ }^{\circ} \mathrm{C} / \mathrm{s}$. In deposition with arc of $5 \mathrm{~kW}$ power cooling rate obviously increases and makes $30 \div 50{ }^{\circ} \mathrm{C} / \mathrm{s}$.

Observed "dips" in change of structure state of the deposit (Fig. 7) are related with the increase of deposit's temperature above $\alpha \rightarrow \gamma$ transformation temperature. This results in reverse transformation of the initial structure in austenite. Heating of lower layers of the deposit above Acs temperature is stopped in $25 \mathrm{~s}$ from melting start at low $1 \mathrm{~kW}$ arc power. Whereas, at high $5 \mathrm{~kW}$ arc power this process is terminated only after $45 \mathrm{~s}$. This results in more uniform distribution of structural constituents on thickness of the deposit at low arc power and, respectively, more inhomogeneous structure at high arc power. 
Analysis of received results show that rise of deposit thickness provokes change of structure from ferrite-pearlite ( $48 \%$ of ferrite, $52 \%$ of pearlite) into ferrite-bainite (5\% of ferrite, $95 \%$ of bainite). Increase of portion of bainite constituent in the deposit is related with formation of relatively high cooling rates $\left(10 \div 15^{\circ} \mathrm{C} / \mathrm{s}\right)$ at quick cooling of thin layers of the deposit $(1 \mathrm{~mm})$. Increase of arc heat input leads to overheating of liquid metal, rise of maximum pool temperature to $1750 \div 1850{ }^{\circ} \mathrm{C}$, rise of cooling rate from 15 to $25^{\circ} \mathrm{C} / \mathrm{s}$ and, as a result, build-up of portion of martensite in the deposited layer structure.

Calculated changes of $\mathrm{C}, \mathrm{Si}$ and $\mathrm{Mn}$ content on thickness of the deposited layers is presented in figure 8 . The calculations, carried on the proposed model, show that periodic changes in structure, composition and properties of the material take place in the deposited bead. Long-term staying of the deposited metal above Ac1 temperature in the austenite area results in noticeable redistribution of carbon on bead thickness.

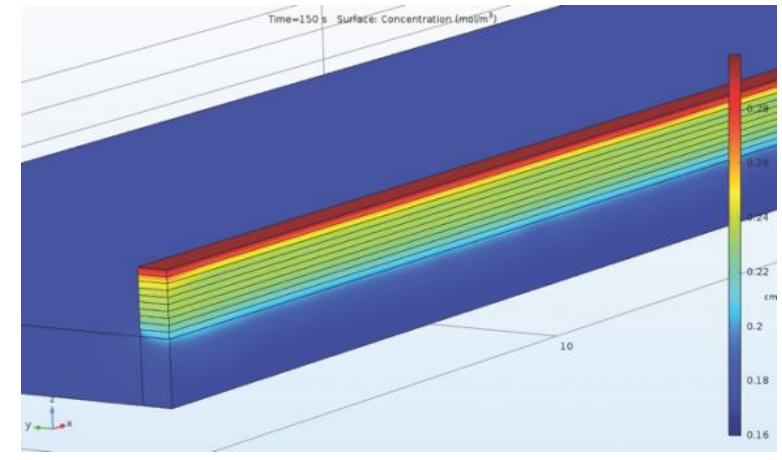

(a)

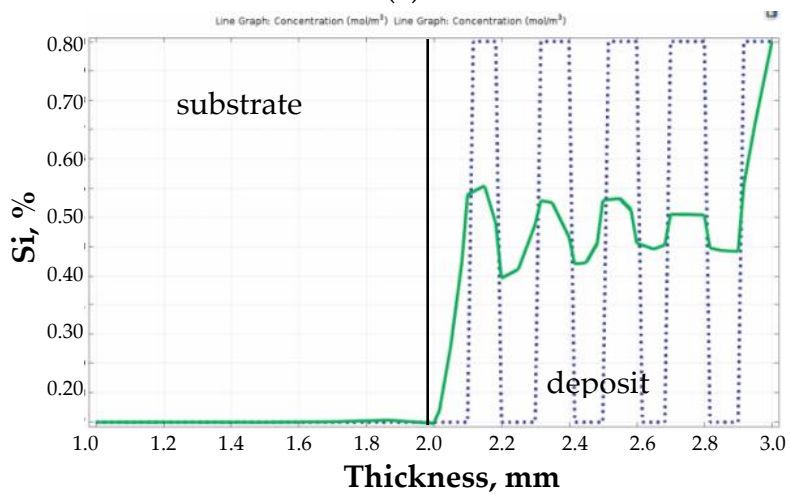

(c)

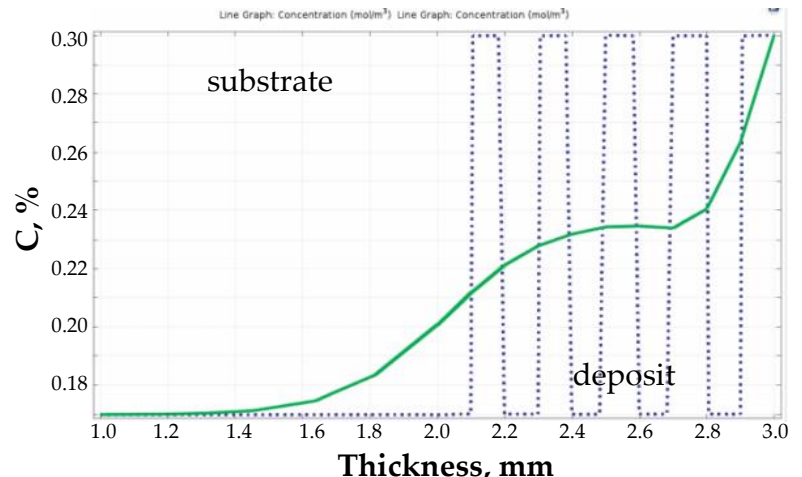

(b)

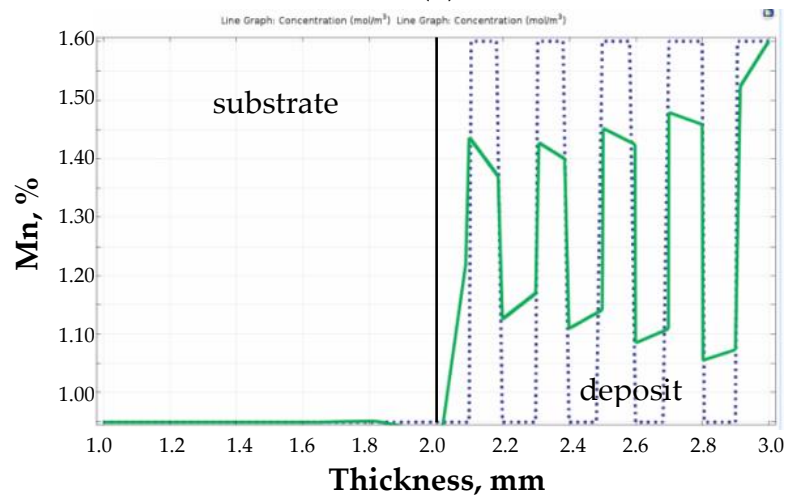

(d)

Fig. 8. Distribution of the content of elements in the additive deposited layers by thickness: a) 3D view carbon distribution, b) carbon, c) silicon, d) manganese; $\bullet \bullet \bullet \bullet-$ initial content, - - content after $150 \mathrm{~s}$

Higher carbon diffusion coefficient in ferrite area and increased time of keeping the deposited layers in the austenite area lead to more uniform distribution of carbon on deposit thickness (Fig. 8b). Reduced diffusion mobility of silicon (Fig. 8c), and, in particular, of manganese (Fig. 8d) leads to preservation of periodic change of content of these elements in the deposited bead. Difference in content of elements in the layers reduces with increase of thickness of deposited layers.

It can be concluded based on the received results that increase of duration of additive process of layers deposition will promote homogenization of composition of part being formed. Rise of arc power results in intensification of process of the deposit homogenization.

\section{Conclusions}

1. Application of additive process to deposit formation allows developing artificial periodic structures having controlled anisotropy of properties on structure, composition, thermal-physical properties.

2. During deposition in additive manufacturing it is reasonable to use preheating of the substrate by means of "idle" run of the arc. Application of preheating allows significantly reducing stresses on substrate bead boundary to $50 \div 70 \mathrm{MPa}$.

3. Time between the passes of the initial point by neighbor arc heat sources shall be kept in $5 \div 30 \mathrm{~s}$ range. It can be regulated by a distance between heat sources and wire feed rate.

4. Increasing the arc power results in a change in the structure deposition from the ferrite-bainite to bainitemartensite, in which the bainite portion in the deposition is $49 \%$, martensite $42 \%$, and ferrite $9 \%$. 
Conflicts of Interest: The authors declare no conflict of interest.

\section{References}

[1] Coykendall J., Cotteleer M., Holdowsky J., Mahto M., 3D opportunity in aerospace and defense: additive manufacturing takes flight, Deloitte University Press 2014, Westlake.

[2] Grigorenko G.M., Shapovalov V.A., Zhukov V.V., Additive manufacturing of metal products (Review), The Paton Welding Journal, 2016, No. 5-6, 148-153. [Hyperlink]

[3] Cotteleer M., Joyce J., 3D opportunity - additive manufacturing paths to performance, innovation, and growth, Deloitte Rev., 2014, 14.

[4] Wong K.V., Hernandez A., A Review of Additive Manufacturing, ISRN Mechanical Engineering, 2012. [CrossRef]

[5] Dave V.R., Matz J.E., Eagar T.W., Electron Beam Solid Freeform Fabrication of Metal Parts, 1995 International Solid Freeform Fabrication Symposium, 1995, University of Texas at Austin, 64-70.

[6] Jandric Z., Labudovic M., Kovacevic R., Effect of heat sink on microstructure of three-dimensional parts built by welding-based deposition, International Journal of Machine Tools and Manufacture, 2004, Vol. 44(7-8), 785-796. [CrossRef]

[7] Acheson R., Automatic welding apparatus for weld build-up and method of achieving weld build-up, 1990, US patent no. 4952769 .

[8] Shapovalov V.A., Grigorenko G.M., Control of metal structure in process of solidification, Advanced Electrometallurgy, 2015, No. 2, 51-54.

[9] Gururaja Udupa, Shrikantha Rao S., Gangadharan K.V., Functionally Graded Composite Materials: An Overview, Procedia Materials Science, 2014, Vol. 5, 1291-1299. [CrossRef]

[10] Mahamood R.M., Akinlabi E.T., Laser-metal deposition of functionally graded Ti6Al4V/TiC, Materials E Design, 2015, Vol. 84(5), 402-410. [CrossRef]

[11] Kroupa A., Modelling of phase diagrams and thermodynamic properties using Calphad method - Development of thermodynamic databases, Computational Materials Science, 2013, Vol. 66, 3-13. [CrossRef]

[12] https://www.comsol.com/comsol-multiphysics

[13] Kostin V.A., Grigorenko G.M., Peculiarities of formation of structure of 3D part of steel S460M in additive metallurgical technology, Advanced Electrometallurgy 2017, No.3 (128), 33-42.

[14] Paton B.E., Investigations and developments of E. O. Paton Electric Welding Institute for modern power engineering, Technical diagnostics and non-destructive testing, 2014, No.1, 3-11.

[15] Kostin V.A., Grigorenko G.M., Zhukov V.V., Modelling of metallurgical additive process of development of structures from 09G2S steel, Advanced Electrometallurgy, 2017, No.2 (127), 35-44.

[16] Blanter M.E., Phase transformations during thermal treatment of steels, Moscow, GNTIL on ferrous and nonferrous metallurgy, 1962, 268.

(C) 2019 by the authors. Submitted for possible open access publication under the terms and conditions of the Creative Commons Attribution (CC BY) license (http://creativecommons.org/licenses/by/4.0/). 